\title{
Deficiency in Translesion DNA Polymerase $\zeta$ Induces an Innate Immune Response
}

Sara K. Martin ${ }^{1,2}$, Junya Tomida ${ }^{1,3}$, and Richard D. Wood ${ }^{1,2}$

${ }^{1}$ Department of Epigenetics \& Molecular Carcinogenesis, The University of Texas MD Anderson Cancer Center, Smithville, Texas, USA and ${ }^{2}$ The University of Texas MD Anderson Cancer Center UT Health Graduate School of Biomedical Sciences

${ }^{3}$ Present address: Department of Biological Sciences, University of North Carolina, Charlotte, USA

*To whom correspondence should be addressed: rwood@mdanderson.org, tel (512) 237-9431, fax (512) 237-6532 


\section{ABSTRACT}

DNA polymerase pol $\zeta$ is regarded as a specialized DNA polymerase for bypass of DNA lesions. In mammalian cells, pol $\zeta$ also contributes to genomic stability during normal DNA replication. Disruption of Rev3/ (the catalytic subunit of pol $\zeta$ ) is toxic to cells and mice, with increased constitutive chromosome damage, including micronuclei. As the cellular manifestations of this genomic stress have remained unexplored, we measured genome-wide transcriptional changes by RNA-seq in pol $\zeta$-defective cells. Expression of 1117 transcripts was altered by 4-fold or more in Rev3/ knockout mouse embryonic fibroblasts (MEFs), with a pattern showing an induction of an innate immune response. We validated the increased expression of known interferon-stimulated genes (ISG) at the mRNA and protein levels. We found that the cGAS-STING axis, which senses cytosolic DNA, drives ISG expression in Rev3/ knockout MEFs. These results reveal a new genome protective function of pol $\zeta$ and indicate that inhibition of pol $\zeta$ may be therapeutically useful by simultaneously increasing sensitivity to genotoxins and inducing a cytotoxic innate immune response. 


\section{INTRODUCTION}

Mammalian genomes encode an array of translesion DNA polymerases, which provide a diverse tool kit to tolerate assorted genomic lesions [1]. While most translesion DNA polymerases are required for cells to survive various exogenous genotoxic assaults, they are not essential for mammalian development or unchallenged cellular survival [1]. An exception is DNA polymerase $\zeta$ (pol $\zeta$ ) whose catalytic subunit is encoded by the Rev3/ gene [2]. Germline disruption of Rev3/ results in embryonic lethality in mice [3-5]. The indispensable nature of pol $\zeta$ likely stems from inadequately understood genome protective functions. Disruption of Rev3/ in B cells or keratinocytes in mice leads to acute genomic stress in the target tissues [6-10]. Primary mouse embryonic fibroblasts (MEFs) rapidly accumulate chromosome breaks at the first metaphase following Rev3l disruption [11]. Loss of pol $\zeta$ in primary MEFs cripples cell proliferation, with the cells failing to replicate past roughly two rounds of cell division following Rev3/ disruption [11]. The dramatic growth suppression in Rev3/ knockout MEFs appears to be ameliorated by blunting DNA damage quality control responses, for example by p53 deletion [12] or T-antigen expression [11] (which inhibits p53 and other targets). However, p53 deletion utterly fails to rescue embryonic lethality of Rev3/ disruption in mice [12-14]. This implies that there are additional, p53-independent, growth suppressive responses to the genomic strain caused by Rev3/ disruption. We set out to clarify the consequences of the constitutive genomic stress induced by the loss of pol $\zeta$ in mammalian cells. Starting with an unbiased transcriptome wide approach, we discovered that loss of pol $\zeta$ induces constitutive activation of an innate immune 
response. Further we found that the cytosolic nucleic acid sensor, cGAS, and its downstream signalling partner STING drive this innate immune response in absence of functional pol $\zeta$. Given that the cGAS-STING axis can inhibit cell growth, this gives a potential explanation for why loss pol $\zeta$ function is remarkably toxic to proliferating cells.

\section{RESULTS \& DISCUSSION}

\section{A shortened REV3L construct rescues known phenotypes of pol $\zeta$ disruption}

In order to dissect the consequences of the poorly resolved genome protection function of pol $\zeta$, we set up a complementation system using T-antigen immortalized mouse embryonic fibroblasts (MEFs) [11] either with a pol $\zeta$ proficient background, Rev3l heterozygous (HET) background, or a pol $\zeta$ deficient background, Rev3l knockout (KO). A biochemically active shortened human REV3L construct, TR4-2 [15] (Fig 1A) with an N-terminal Flag-HA tag was stably expressed in Rev3l KO MEFs (Fig 1B, Fig S1A). In order to test that our complementation system was in fact addressing both external and endogenous genome protective functions of pol $\zeta$, we tested both cellular sensitivity to cisplatin and formation of micronuclei in unchallenged cells, one marker of genomic instability. As expected Rev3/ KO + empty vector MEFs were hypersensitive to cisplatin relative to the Rev3l HET MEFs + empty vector (Fig 1C, Fig S1B). Stable expression of TR4-2 in Rev3/ KO MEFs reversed the hypersensitivity to cisplatin (Fig 1C, Fig S1B). This indicates that in this context TR4-2 can restore REV3L's function in DNA damage tolerance. Consistent with large scale genomic stress, $\sim 15-23 \%$ of unchallenged Rev3l KO MEFs had at least one micronucleus, relative to Rev3/ HET MEFs which had a 
micronucleus frequency of $\sim 1-3 \%$ (Fig 1D). Stable TR4-2 expression in Rev3/ KO MEFs restored micronucleus frequency to near-normal, showing that TR4-2 can restore some Rev3/ genome protective functions. We used this isogenic system as a tool to probe the unknown consequence of the loss of pol $\zeta$.
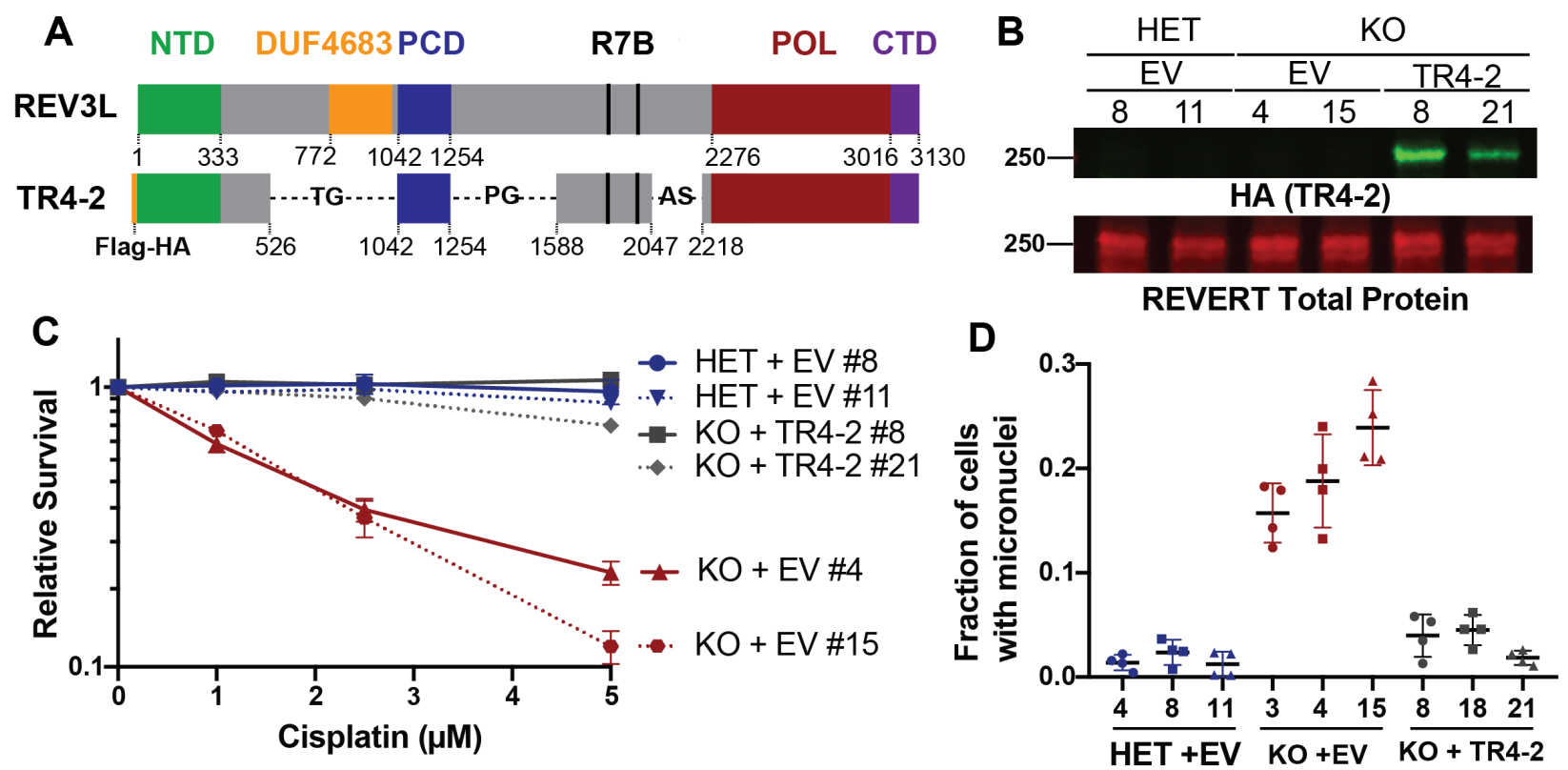

Figure 1: Shortened REV3L construct rescues phenotypes of pol $\zeta$ disruption

A) Schematic of full-length human REV3L and human REV3L construct, TR4-2. TR4-2 retains most conserved domains and binding sites of REV3L including the regions that coordinate interactions with the accessory subunits of pol $\zeta$, the C-terminal domain (CTD, purple) the two REV7 binding sites (R7B, black), and a positively charged domain (PCD) of uncertain function. The B-family catalytic core is formed by folding of the $\mathrm{N}$ terminal domain (NTD, green) and the polymerase domain (POL, red) [2]. B) Immunoblot with HA antibody showing stable expression of TR4-2 with an N-terminal Flag-HA tag in Rev3/ KO MEF clones. Full blots are shown in Fig S2. C) Stable expression of TR4-2 in Rev3/ KO MEF clones reverses hypersensitivity to cisplatin. MEFs were exposed to the indicated cisplatin concentrations for $48 \mathrm{~h}$ and relative 
survival was quantified with the ATPlite assay. D) Stable expression of TR4-2 decreases micronuclei formation in unchallenged Rev3/ KO MEF clones.

\section{Loss of polymerase $\zeta$ alters the transcriptome}

In order to uncover the type of stress occurring in cells lacking pol $\zeta$, we performed genome-wide mRNA sequencing on a controlled set of immortalized clones: Rev3/ HET + empty vector, Rev3l KO + empty vector and Rev3l KO + TR4-2. To focus on major changes, we set a strict threshold $\left(>|2| \log _{2}\right.$ fold change and FDR $\left.<0.05\right)$. Expression analysis of 17,346 mapped transcripts revealed that 1117 transcripts were either upregulated or downregulated in the Rev3l $\mathrm{KO}+$ empty vector relative to the Rev3I HET + empty vector MEFs (Fig 2A). The majority ( 68\%) were upregulated (Fig 2A). These upregulated or downregulated genes displayed no statistically significant enrichment or depletion for DNA replication or canonical DNA damage sensing pathways. This is not completely unexpected given that p53 promotes much of the transcriptional response to DNA damage, while our MEFs have inactivated p53 due to large T-antigen immortalization. In these immortalized high passage cells, we are likely to observe stable transcriptional alterations, rather than an acute response.

Instead the upregulated genes displayed an enrichment in immune systemrelated pathways, as revealed by gene ontology analysis (Fig 2B). Upstream regulator analysis was used to analyze all differentially expressed genes. This revealed that the alterations in the transcriptome are consistent with activation of positive regulators of the interferon response, including key transcription factors in this pathway, IRF3 and IRF7 (Fig 2C). Importantly the predicted activation of IRF3 and IRF7 was reversed by 
expression of the Rev3/ TR4-2 cDNA, showing that these results stem from a function of Rev3l. The same trends were also observed by applying a substantially lower threshold $\left(\log _{2}\right.$ FC $\left.>|0.5|\right)$ for differentially expressed genes. This increased the dataset to 2071 differentially expressed transcripts. Pathway analysis showed a negative correlation with predicted TRIM24 activation. TRIM24 suppresses interferon-stimulated gene expression [16], confirming that our data is consistent with expression of interferon stimulated genes.

To explore whether our data set is in fact consistent with an interferon response, we analyzed a curated set of 25 known interferon stimulated genes and observed increased expression in the Rev3/ KO relative to the Rev3/ HET MEFs, which was partially reduced by TR4-2 stable expression (Fig 2D). Together our results reveal that disruption of pol $\zeta$ promotes induction of interferon-stimulated genes. 


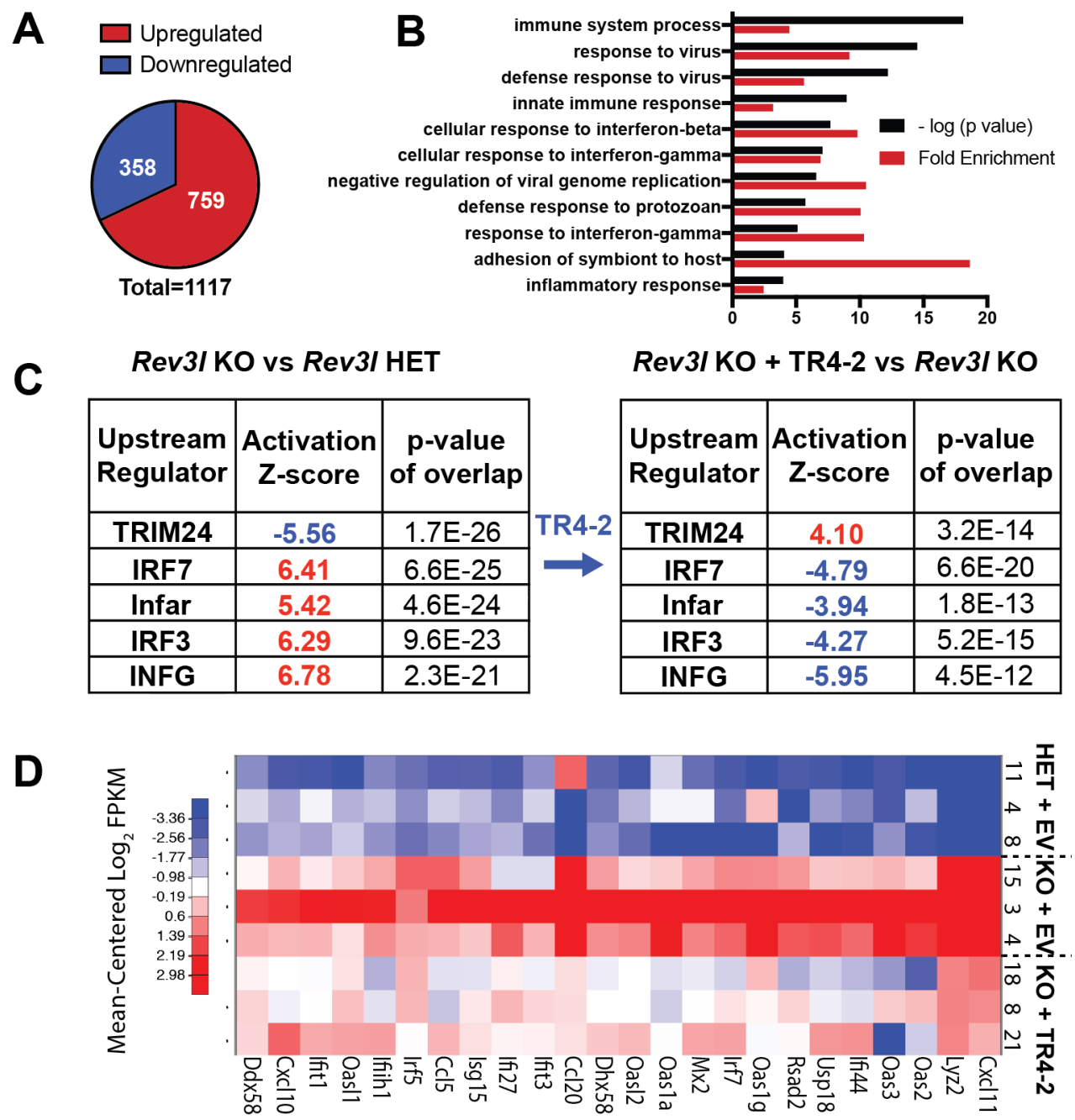

Figure 2: Cells deficient in DNA polymerase $\zeta$ have an altered transcriptome.

A) Differentially expressed genes in Rev3/ KO + empty vector relative to Rev3/ HET + empty vector using the threshold of a $\log _{2}$ fold change of $>|2|$ and a false discovery rate of $<0.05$. B) Top $10 \mathrm{GO}$ (Gene Ontology) terms reveal enrichment of immune system related genes in upregulated genes in Rev3/ KO MEFs. C) Upstream regulator analysis reveals the data set is consistent with predicted activation of positive regulators of an interferon response in Rev3/ KO MEFs. D) Heatmap of a set of 25 known interferonstimulated genes. 


\section{Disruption of Rev3l induces interferon-stimulated gene expression driven by the cGAS-STING axis}

Given that our complemented cell lines were generated using lentivirus constructs and grown continually under selection, we moved to validate the results in the parental Rev3/ KO and Rev3/ HET MEF cell lines and one additional set of cell lines to limit extraneous variables. We confirmed an increase in mRNA expression of specific interferon stimulated genes in the Rev3/ KO MEFs relative to the control cell lines, including key chemokines (Fig 3A). In order to extend these findings to the protein level, we examined interferon stimulated gene products by immunoblotting. Corresponding to an increase in mRNA levels, we also observed an increase in protein levels of known interferon stimulated genes, MDA5 (encoded by the IFIH1 gene), ISG15, and viperin (encoded by the RSAD2 gene) (Fig 3B). Together these data indicate that an interferon branch of the innate immune system may be activated due to disruption of pol $\zeta$ function. Since it seems unlikely that pol $\zeta$ plays a direct role in transcriptional regulation, the next obvious question is how and why loss of pol $\zeta$ induces the expression of interferon stimulated genes.

The major consequence of pol $\zeta$ disruption in unchallenged mammalian cells is increased genomic instability as evidenced by multiple markers including $\mathrm{Y}-\mathrm{H} 2 \mathrm{AX}$ foci, chromosome fragmentation and aberrations, and micronuclei [10-12,17] (Fig 1D). Therefore, it seems likely that this transcriptional response ultimately stems from the vast genomic damage induced by loss of pol $\zeta$ function. Consistent with this hypothesis, the innate immune system not only can recognize and mount an interferon response to foreign DNA, but also can respond to endogenous DNA that has escaped from the nucleus. In some instances, this response can halt cell growth providing organisms to shut down propagations of virally infected cells and cells with dangerously fragmented genomes. 
Mammalian cells have a host of cytosolic nucleic acid sensors that patrol the cytosol for DNA. One of these, cGAS, is increasingly recognized to be of paramount importance in the induction of an interferon response to both exogenous and endogenous cytosolic DNA [18]. When cGAS binds to double stranded DNA, it activates its enzymatic activity and results in the production of cGAMP, a cyclic dinucleotide. cGAMP binds to the STING receptor on the membrane of endoplasmic reticulum, resulting in activation of kinases including TBK1 which can in turn phosphorylate and activate IRF3, a central transcription factor in the interferon response.

Given that cGAS-STING axis has been implicated specifically in responding to endogenous DNA damage and has been correlated with micronuclei formation, we asked whether cGAS-STING promotes the induction of expression of interferon stimulated genes due to loss of function of pol $\zeta$. Consistent with most MEFs having a functional innate immune system, both Rev3/ KO and HET MEF cell lines expressed both CGAS and STING (Fig 3C). We noted a decrease in STING expression in Rev3/ KO MEFs, which is consistent with a constitutive activation of the cGAS-STING pathway, as cGAS activation leads to a negative feedback loop resulting in STING degradation $[19,20]$. Importantly, we detected an increase of IRF3 phosphorylated at S888 (corresponding to S396 in humans) indicative of IRF3 activation in Rev3/ KO MEFs [21,22] (Fig 3D).

This led us to investigate if cGAS-STING drives expression of interferonstimulated genes upon loss of pol $\zeta$. Knockdown of either cGAS or STING significantly reduced the mRNA expression of selected interferon stimulated genes as well as the protein levels (Fig 4A-D). In addition, depletion of cGAS or STING in Rev3I KO MEFs markedly reduced S888 phosphorylation of IRF3 (Fig 4E). Together this indicates that 
disruption of pol $\zeta$ function promotes activation of an innate immune response driven by the cGAS-STING axis.
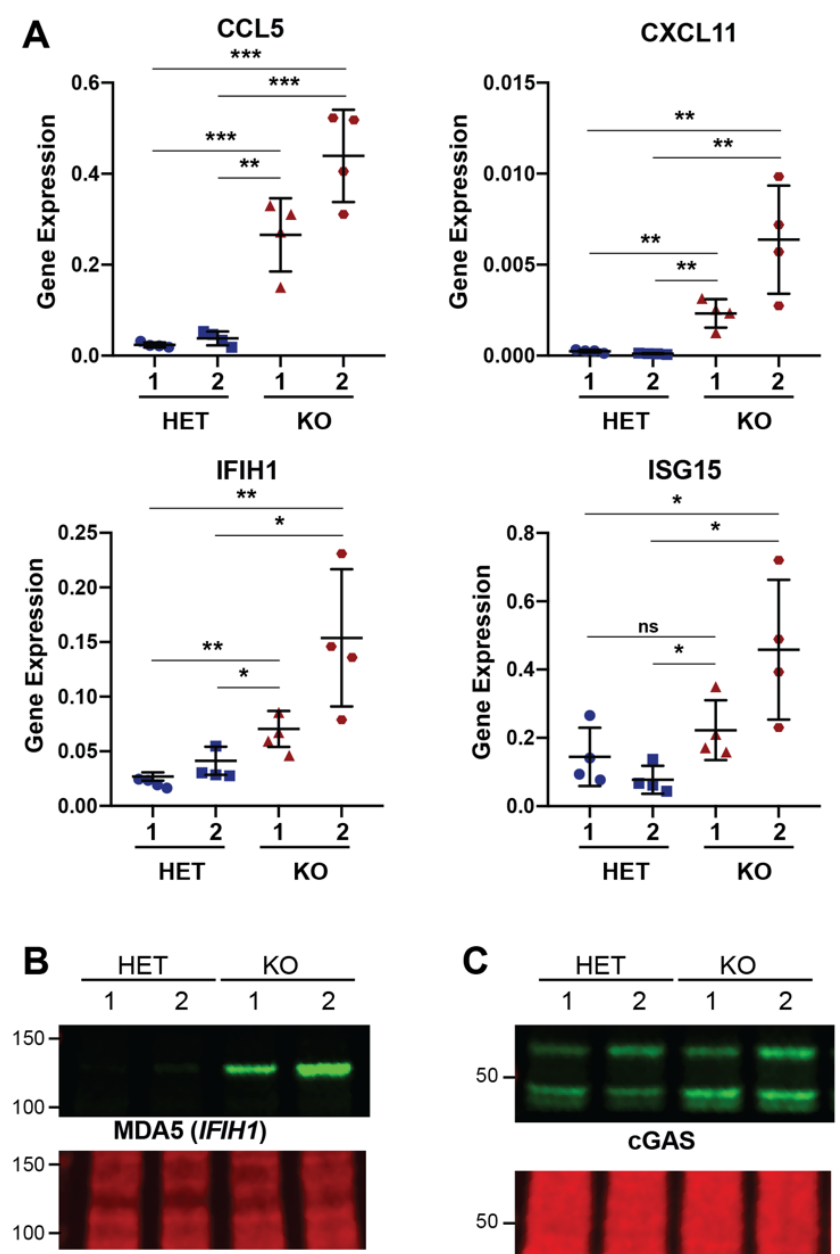

REVERT Total Protein
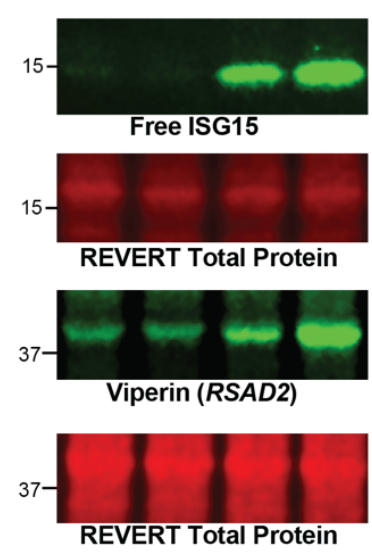
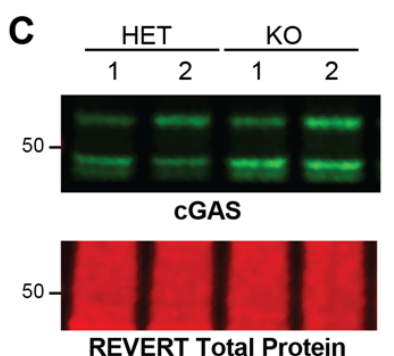

STING

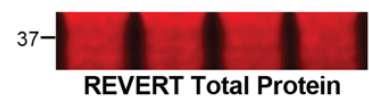

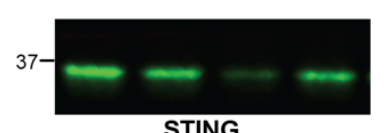

RSAD2



IRF7

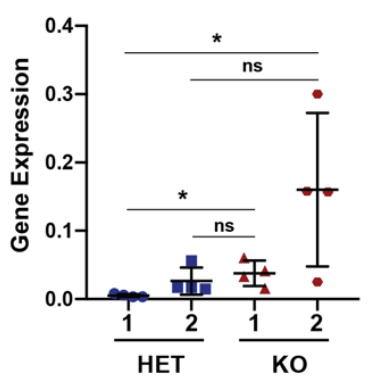

D $\frac{\mathrm{HET}}{12} \frac{\mathrm{KO}}{1} 2$
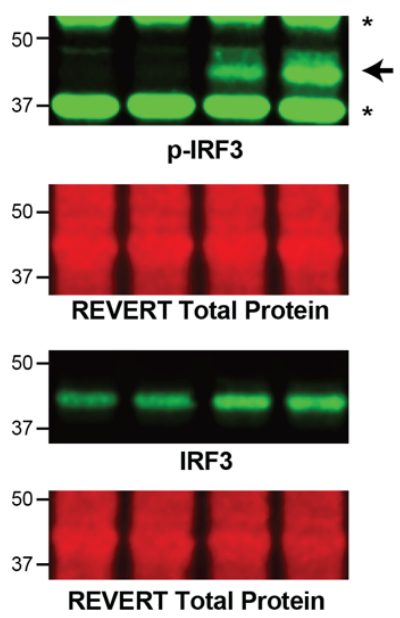

Figure 3: Disruption of Rev3l results in increased expression of interferon

stimulated genes and proteins. A) Gene expression $\left(2^{-\Delta C t}\right)$ of selected interferon 
stimulated genes normalized to HPRT detected by qRT-PCR. Error bars represent standard deviation. Unpaired student t-test, ${ }^{*}=p<0.05,{ }^{* *}=p<0.01$ and ${ }^{* * *}=p<$ 0.001. B) Immunoblots showing increased protein levels of interferon stimulated genes, MDA5 and ISG15. C) Immunoblot showing presence of components of the innate immune system, cGAS and STING, in MEFs, with reduced STING in pol $\zeta$ knockout cells. D) Enhanced phosphorylation of S888 of IRF3 (corresponding to S396 in humans) in Rev3/ KO MEFs. Full blots are shown in Fig S3. 



Rev3I KO 2
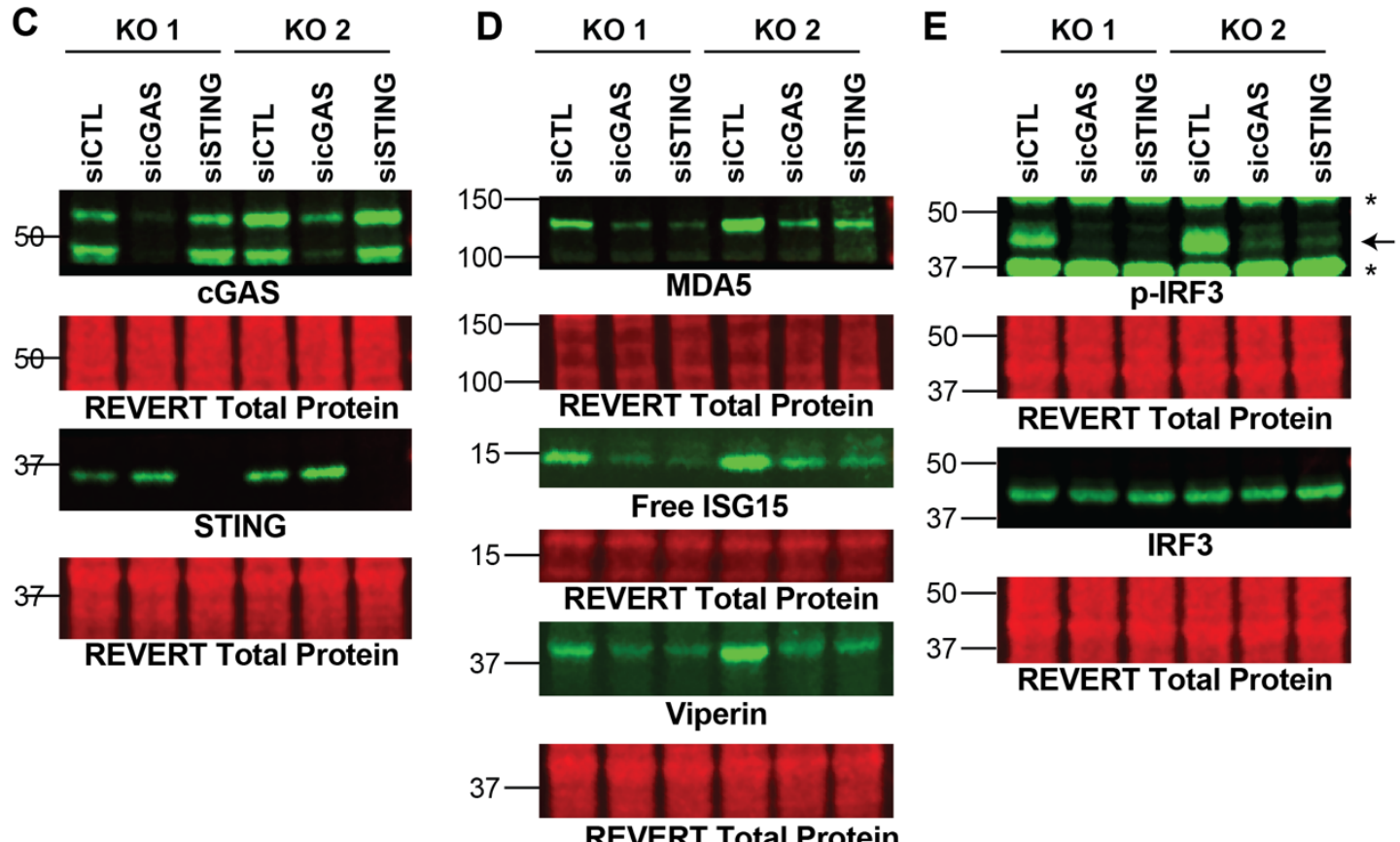

REVERT Total Protein
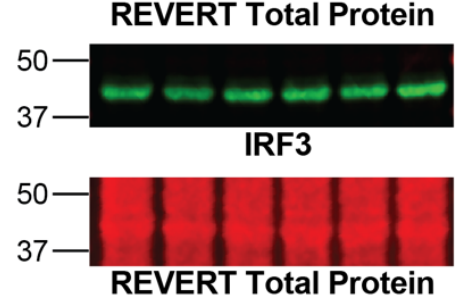

Figure 4: The cGAS-STING axis promotes expression of interferon stimulated genes due to loss of pol $\zeta$ function. A) Knockdown of cGAS or STING reduces mRNA expression of CCL5, CXCL11, RSAD2 (which encodes Viperin protein), IFIH1 (which 
encodes MDA5) as detected by qRT-PCR in Rev3/ KO 1. Gene expression (2- $\left.{ }^{-4 t}\right)$ of selected interferon stimulated genes normalized to HPRT detected by qRT-PCR. Error bars represent standard deviation. Unpaired student t-test, ${ }^{*}=p<0.05,{ }^{* *}=p<0.01$, ${ }^{* * *}=p<0.001$ and $^{* * * *}=p<0.0001$. B) Same as in A except with Rev3/ KO 2. C) Efficient knockdown of cGAS or STING protein levels. D) MDA5, ISG15, and Viperin protein levels decrease with cGAS and STING knockdown. E) Phosphorylation of S888 in mouse (analogous to the human S396) of IRF3 in Rev3/ KO MEFs decrease with knockdown of cGAS and STING. Equal protein loading was monitored by REVERT total protein stain (Fig S4).

\section{An innate immune response cause by loss of pol $\zeta$ function}

Pol $\zeta$ stands apart from the other translesion polymerases in that it is required for mammalian development and proliferation of primary cells. Now we can add that in addition to activating p53-dependent responses, disruption of pol $\zeta$ function invokes a prominent innate immune response promoted by the cGAS-STING pathway.

It is remarkable that disruption of an enzyme commonly thought of as a specialized transleion synthesis polymerase can lead to a constitutive innate immune response. Recently, cells with loss of function of key DNA repair enzymes, RNaseH2, BRCA2, and BLM have been shown to have an elevated cGAS-STING response that correlates with an increase in micronuclei that colocalize with cGAS [23-26]. There are several sources of DNA damage that may give rise to a sustained response including cytosolic mitochondrial DNA [27] and cytosolic DNA arisen from stalled and processed replication forks [28]. DNA stress may continually arise from likely collapse of DNA replication forks in the absence of pol $\zeta$, which could promote formation of micronuclei and also release small fragments of DNA. Further, some nuclear genes including pol $\zeta$ 


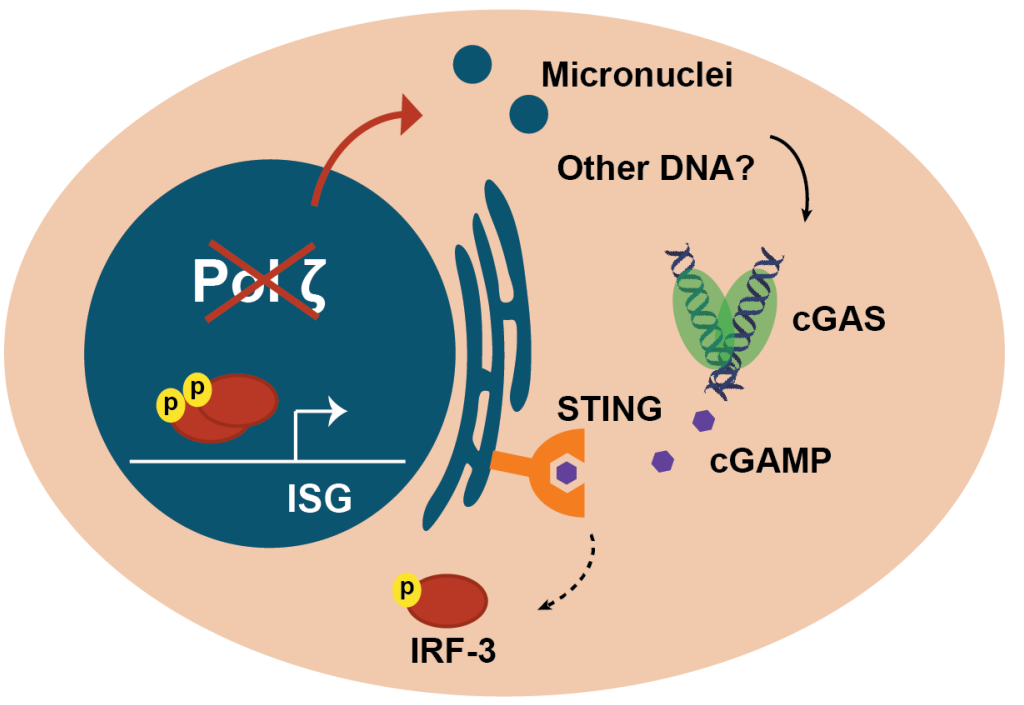

Figure 5: Model for disruption of pol $\zeta$ triggering an innate immune response. Loss of pol $\zeta$ induces genomic damage that results in accumulation of forms of cytosolic DNA, including micronuclei at a minimum. This results in DNA binding of cGAS and activation of STING which indirectly promotes phosphorylation and activation of IRF-3. This results in expression of interferon stimulated genes (ISG).

control mitochondrial DNA integrity, and there is evidence that mitochondrial function is compromised without pol $\zeta$ [29]. It remains to be seen whether micronuclei are the primary source of interferon signalling in cells lacking pol $\zeta$, or whether they are more of an indicator of DNA degradation.

An interferon response can result in shutting down cell growth. Specifically, cGAS has been tied to promoting senescence in primary cells [30,31]. Our experiments were performed in T-antigen immortalized MEFs. In addition to blunting p53 activity, large T-antigen has been implicated in impairing an interferon response to nucleic acids [32]. Loss of pol $\zeta$ would likely induce an innate immune response of even greater magnitude in primary MEFs. Primary MEFs lacking pol $\zeta$ only make it approximately two cell divisions before cell growth completely halts, which is accompanied by an increase in senescent cells [11]. An essential function of pol $\zeta$ is also evident from the failure of Rev3/-defective embryos to develop, and the from the inability of Rev3/-defective primary keratinocytes to proliferate in a mouse model $[2,10,11]$. It is possible that cGASSTING drives this severe growth arrest in primary cells due to loss of pol $\zeta$ function.

In addition to widening our understanding of the lengths cell go to protect themselves from the genomic damage induced by impairment of pol $\zeta$, these results 
could have impact on translational approaches. A potential approach, suggested by experiments in laboratory settings, has been to disrupt pol $\zeta$ function to enhance chemotherapeutic effectiveness [33-35]. For example, an inhibitor that impairs the interaction of pol $\zeta$ with the master regulator REV1 has been developed that sensitizes cancer cells and xenograft tumors to cisplatin treatment [36]. Our work suggests that such inhibitors might also induce an interferon response. This approach would have multiple advantages for therapy by enhancing DNA damage sensitivity, limiting induced mutations, and potentially enhancing a cytotoxic immune response on targeted cells.

\section{MATERIALS and METHODS}

\section{Cell Lines}

The immortalized Rev3/ knockout (KO) and heterozygous (HET) mouse embryonic fibroblast (MEF) parental cell lines in this study were as described [11]. In brief, the Rev3/ KO MEFs were generated by T-antigen immortalization of primary MEFs isolated from mouse embryos with one null Rev3l and one floxed allele, followed by ex vivo AdCre deletion of the floxed allele, and clonal selection to ensure a homogenous population with the genotype $\operatorname{Rev} 3 \mathrm{I}^{-\mathrm{I}}$. The Rev3/ HET MEFs were isolated in the same manner expect starting MEFs from embryos with one wild-type and one floxed allele, resulting in MEFs with the genotype $\operatorname{Rev} 3 I^{+/ \Delta}$. The floxed allele was generated by placing loxP sites flanking two conserved exons, corresponding to residues 2776-2860, that contain the three conserved catalytic aspartate residues of REV3L [6]. The null allele replaced these two exons with a lacZ-neo ${ }^{R}$ cassette [5]. In this study two sets of clones were analyzed. Cells were grown in DMEM (Sigma \#5796), 10\% Fetal Bovine Serum (FBS) and 1 X penicillin/streptomycin (Gibco \#15140122). 


\section{Generation of TR4-2 expressing Rev3I KO MEFs}

The TR4-2 construct, a gift from Dr. Wei Yang [15], was cloned into the pCDH backbone with an N-terminal Flag-HA tag as the same previously described for the full length Rev3l cDNA [37]. The pCDH-Flag-HA-TR4-2 or pCDH-Flag-HA empty vector was stably inserted into the MEF cell lines using lentiviral infection as previously described [17]. Three single clones were isolated for analysis and continually grown in 1 $\mu \mathrm{g} / \mathrm{mL}$ of puromycin to ensure stable integration of the construct.

\section{RNA isolation}

RNA was isolated from $1.5 \times 10^{6}$ (Fig 2, RNA seq) $2.5 \times 10^{5}$ cells (Fig 3 , gene expression) or $1 \times 10^{6}$ cells (Fig 4, gene expression), using the RNeasy Kit (Qiagen \# 74104) following the manufacturer's instructions including the on-column DNase I digestion (Qiagen \#79254).

\section{Genome-wide mRNA sequencing}

Library preparation and sequencing

mRNA libraries were prepared using the Illumina TruSeq Stranded mRNA kit following manufacturer's instructions and 75 base paired end sequencing was run on the Illumina HiSeq 3000.

Sequence mapping and identifying differentially expressed genes

The reads were mapped to the mouse genome (mm10) using tophat V2.0.10 and bowtie V2.1.0. Differentially expressed genes which were defined as $>|0.5|$ fold change and $<$ 0.05 FDR were determined using limma_3.20.4, htseq-count V0.6.0 
and edgeR_3.8.6. More stringent cut-offs for fold change were used for various analyses as described below.

\section{Analysis of differentially expressed genes}

For gene ontology analysis, genes upregulated more than 4-fold with an FDR $<0.05$ were entered into DAVID 6.8 on 02/22/20 and the top 10 GOTERMS_BP_Direct were plotted based on -log( $p$ value) $[38,39]$. For upstream regulator analysis, differential expressed gene both upregulated and downregulated more than 4 fold with an FDR < 0.05. were entered into IPA IPA (QIAGEN Inc., https://www.qiagenbioinformatics.com/products/ingenuity- pathway-analysis). Given that upregulated genes are overrepresented in the Rev3l KO differentially expressed genes, this results in an expected bias for upstream regulators that also predominately result in the upregulation of targeted genes which we see in our data set. Since, bias-corrected z-scores are not reported for upstream regulators with a |bias term| $>0.5$, we've reported the uncorrected z-score here. Given that the majority of differentially expressed genes are upregulated in our dataset, bias is to be expected for transcription regulators that primarily induce expression of genes.

\section{Gene expression analysis}

High Capacity cDNA Reverse Transcription (Applied Biosciences \#4368814) was used to prepare cDNA from 1000 ng of total RNA from each sample. qPCR was run iTaq Universal SYBR Green Supermix (Biorad \#1725121) on the Applied Biosystems 7900HT Fast Real-Time PCR System. Gene expression of calculated using the $2^{-\Delta C t}$ method normalizing to the HRPT gene. The following primers (5' to 3') were used for the mouse target genes: 
HRPT forward: CTGGTGAAAAGGACCTCTCG

HRPT reverse: CAAGGGCATATCCAACAACA

CCL5 forward: ACGTCAAGGAGTATTTCTACAC

CCL5 reverse: GATGTATTCTTGAACCCACT

CXCL11 forward: AGGAAGGTCACAGCCATAGC

CXCL11 reverse: CGATCTCTGCCATTTTGACG

RSAD2 forward: ATAGTGAGCAATGGCAGCCT

RSAD2 reverse: AACCTGCTCATCGAAGCTGT

IFIH1 forward: CGGAAGTTGGAGTCAAAGC

IFIH1 reverse: TTTGTTCAGTCTGAGTCATGG

ISG15 forward: CTAGAGCTAGAGCCTGCAG

ISG15 reverse: AGTTAGTCACGGACACCAG

IRF7 forward: CAATTCAGGGGATCCAGTTG

IRF7 reverse: AGCATTGCTGAGGCTCACTT

\section{Immunoblotting}

Cell were lysed ( 3 million cells $/ 100 \mu \mathrm{L}$ ) in lysis buffer (Tris-HCl: $50 \mathrm{mM}, \mathrm{pH} 7.5$, $\mathrm{NaCl} 250 \mathrm{mM}$, EDTA $1 \mathrm{mM}$, Triton X-100 0.1\%, 1 X Protease/Phosphatase Inhibitor Cocktail CST \#5872) for 30 min on ice with mixing every $10 \mathrm{~min}$. Debris was pelleted by centrifugation at $15,000 \times \mathrm{g}$ for $20 \mathrm{~min}$ at $4^{\circ} \mathrm{C}$. Protein amounts were quantified using Biorad Protein Assay (Biorad \#500-0006) and a bovine serum albumin standard curve (Biorad \#500-0007) following manufacturer's instructions. The samples were denatured using 4 x loading buffer (LI-COR \#928-40004). $25 \mu \mathrm{g}$ of protein / well and Precision Plus Protein All Blue Standards (Biorad \#161-0373) were run on 4-20\% polyacrylamide gels 
(Biorad \#4561096) in $1 \times$ Tris/Glycine/SDS buffer (Biorad \#161-0772). Protein was transferred to Immobilon-FL PVDF Membrane (Millipore \#IPFL00010) in 1 x Tris/Glycine buffer (Biorad \#161-0772) 20\% methanol. After transfer, membranes were dried. Total protein was measured using REVERT total protein stain kit (LI-COR \#926-11010) following the manufacturer's instructions. Membranes were blocked for $1 \mathrm{~h}$ in $0.5 \mathrm{X}$ Odyssey Blocking Buffer (OBB, LI-COR \# 927-50000) in Tris Buffered Saline (TBS) and then incubated in primary antibody overnight at $4^{\circ} \mathrm{C}$. The primary antibodies were used at the following dilutions in 0.5XOBB/TBS/0.2\% Tween-20. Rabbit anti-HA-Tag (C29F4) (CST \#3724, 1:1000), Rabbit anti-cGAS (Mouse specific) (D3O8O) (CST \#31659, 1:1000), rabbit anti-STING (D2P2F) (CST \# 13647, 1:1000), rabbit anti-MDA-5 (D74E4) (CST \# 5321, 1:1000), rabbit anti-ISG15 (CST \# 2743, 1:500), rabbit anti-Phospho-IRF3 (Ser396) (4D4G) (CST \#4947, 1:1000), rabbit anti-IRF-3 (D83B9) (CST \#4302, 1:1000), mouse anti-viperin (Millipore \#MAB106, 1:250), rabbit anti-STAT1 (D1K9Y) (CST: \#14994, 1:1,000), rabbit anti-TBK1 (D1B4) (CST: \#3504, 1:1,000), and rabbit anti-Phospho-TBK1 (S172) (D52C2) (CST: \#5483, 1:1,000).

After primary incubation membranes were washed three times in TBS/0.1\% Tween-20, and incubated for $1 \mathrm{~h}$ in secondary antibody either goat anti-Rabbit $800 \mathrm{CW}$ (LI-COR \#926-32211) or goat anti-mouse 800CW (Licor 827-08364) diluted 1:20,000 in 0.5 XOBB $/$ TBS $/ 0.2 \%$ Tween-20/0.01\% SDS. After primary incubation membranes were washed three times in TBS/0.1\% Tween-20, rinsed with TBS, then dried and imaged on the LI-COR Odyssey FC.

\section{Knockdown of cGAS and STING protein levels}


600,000 cells were seeded in $10 \mathrm{~cm}$ plates. The next day, cells were transfected with 1 nM of the appropriated siRNA using Lipofectamine RNAiMAX (ThermoFisher \#13778150) following the manufacturer's protocols. The following dicer-substrate short interfering RNAs were used: siCTL (IDT: Negative Control DsiRNA \# 51-01-14-03), sicGAS (IDT: DsiRNA Duplex mm.Ri.Mb21d1.13.1), and siSTING (IDT: DsiRNA Duplex mmRi.Tmem173.13.2). After $48 \mathrm{~h}$, cells were harvested in paired pellets for RNA and protein analysis and flash frozen in liquid nitrogen.

\section{Cisplatin sensitivity}

10,000 cells were seeded in triplicate in 96 well plates. The following day cells were treated with the appropriate concentration of cisplatin or vehicle control. After $48 \mathrm{~h}$, the relative survival of the cells was calculated by using the ATPlite assay (Perkin Elmer \#606016943) following the manufacturer's instructions.

\section{Micronuclei frequency}

20,000 cells per chamber were seeded on four-chamber slides. After $48 \mathrm{~h}$, cells were fixed in $100 \%$ methanol and slides were stained with DAPI. The slides were mounted and imaged. Micronuclei were counted as discrete units distinct from the nucleus.

\section{Statistics}

Unpaired student t-tests were run on qPCR and micronuclei frequency results using Prism 8. 


\section{ACKNOWLEDGEMENTS}

We appreciate helpful discussions and advice from MD Anderson Cancer Center

colleagues. We thank Drs. Yue Lu and Bin Liu for invaluable assistance with expression data analysis. We thank Winnie Cheng, for assistance with the micronuclei experiments.

Studies of pol $\zeta$ in our laboratory funded by National Institutes of Health grant

CA193124, Department of Defense grant W81XWH-17-10239, and the Grady F.

Saunders Ph.D. Distinguished Research Professorship to RDW. SKM was supported by

a CPRIT Research Training Grant award (RP170067). The Next Generation

Sequencing Core was supported by CPRIT grants RP120348 and RP170002.

\section{AUTHOR CONTRIBUTIONS}

SKM designed and performed the experiments, led data interpretation, and drafted the manuscript. JT established the complemented cell line pairs and assisted with the manuscript. RDW assisted with experimental design, data interpretation and writing.

\section{CONFLICT OF INTEREST}

The authors declare that they have no conflict of interest. 


\section{SUPPLEMENTARY FIGURES}
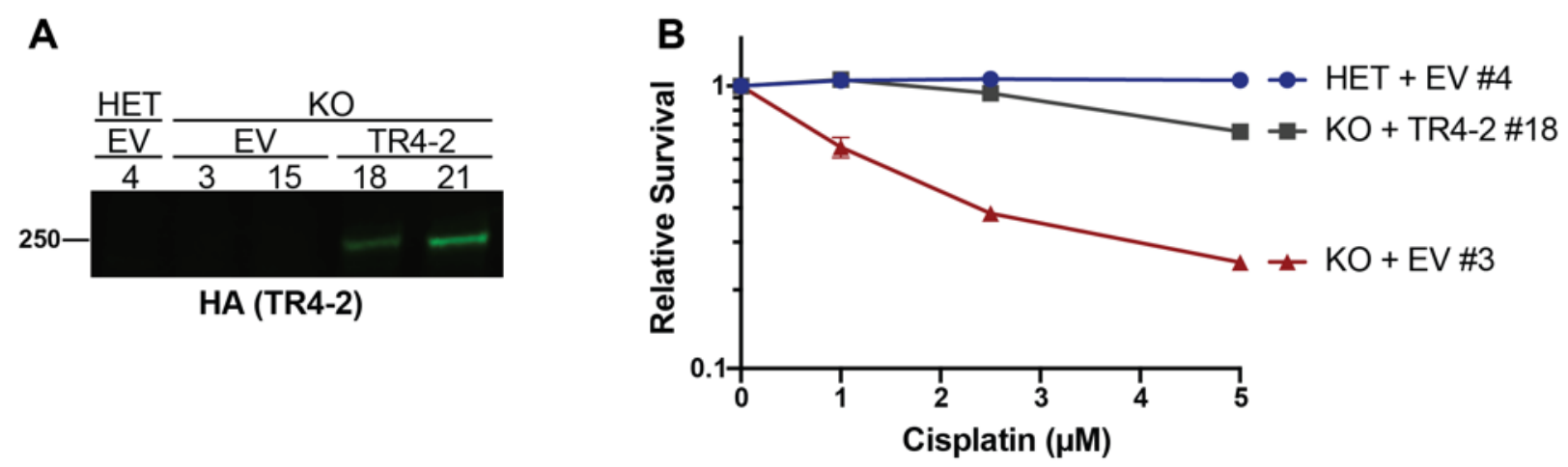

Figure S1: Shortened REV3L construct rescues phenotypes of pol $\zeta$ disruption in an additional set of clones. A) Stable expression of TR4-2 with an N-terminal Flag-HA tag in Rev3/ KO clones as detected by HA immunoblot. See Fig S1 REVERT total protein loading control. B) Stable expression of TR4-2 in Rev3/ KO MEF clones reverses hypersensitivity to cisplatin. MEFs were exposed to the indicated cisplatin concentrations for $48 \mathrm{hr}$ and relative survival was quantified with the ATPlite assay. 

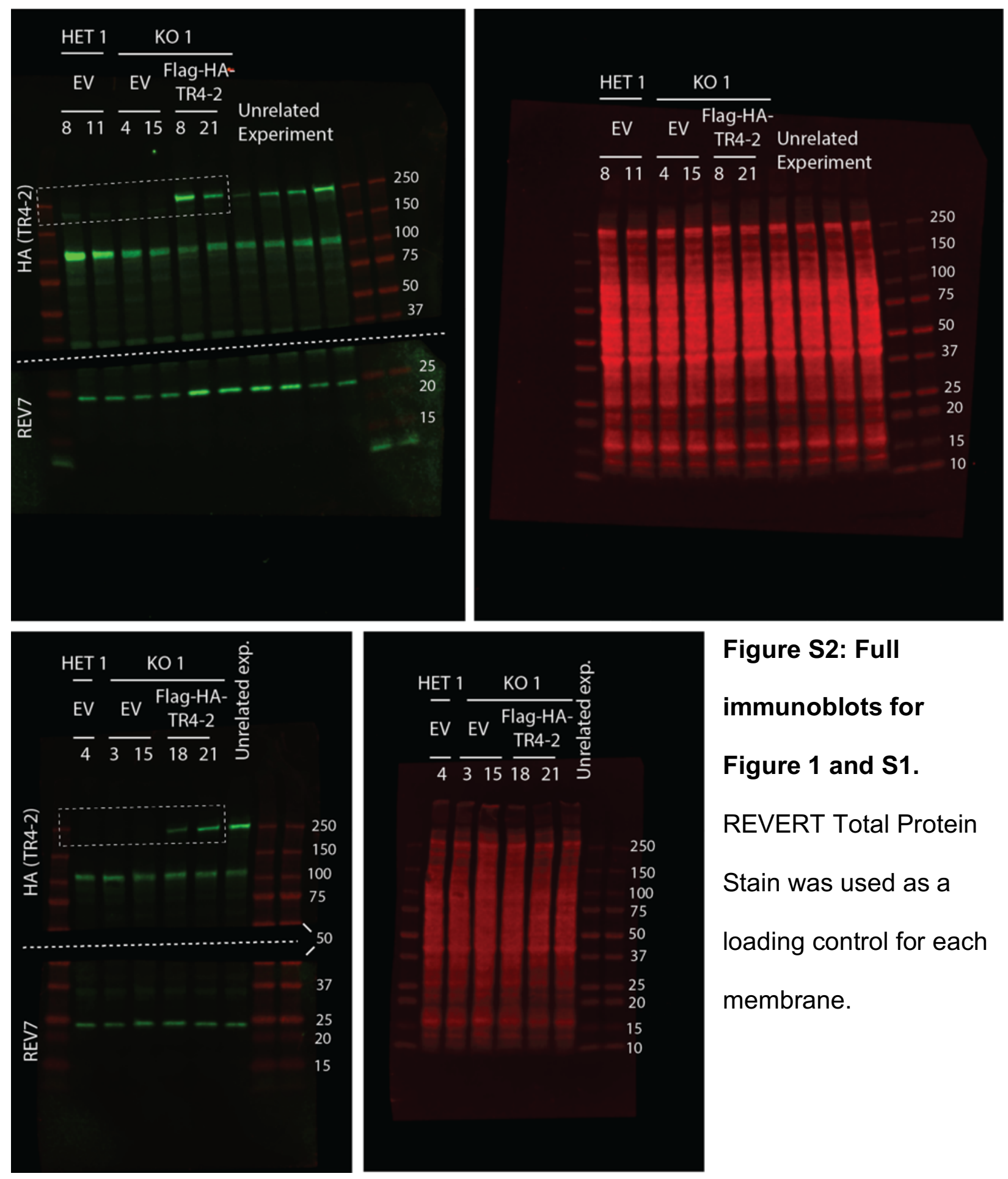

Figure S2: Full

immunoblots for

Figure 1 and S1.

REVERT Total Protein

Stain was used as a

loading control for each

membrane. 

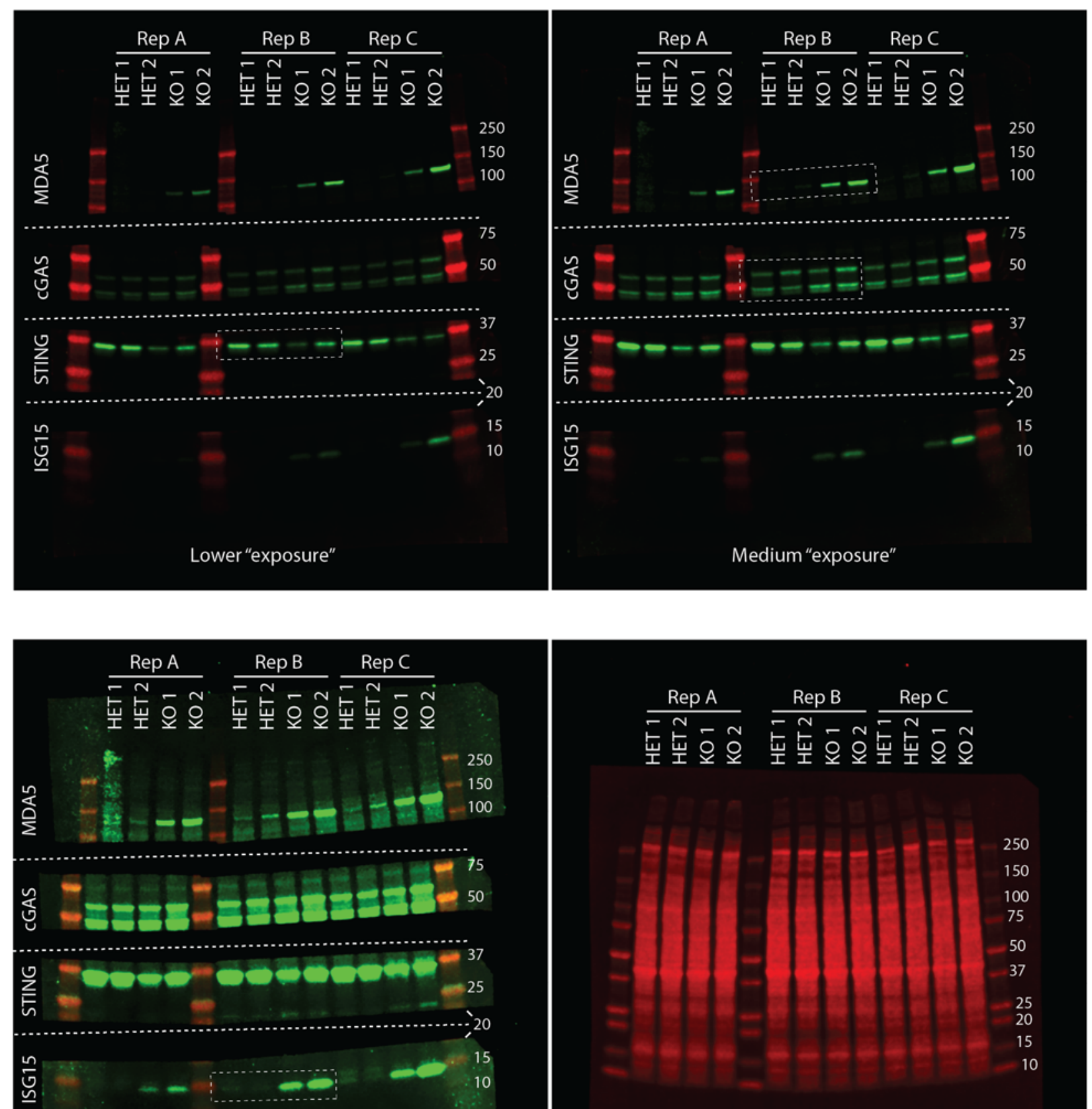

REVERT Total Protein Stain MDA5/CGAS/STING/ISG15 membrane 

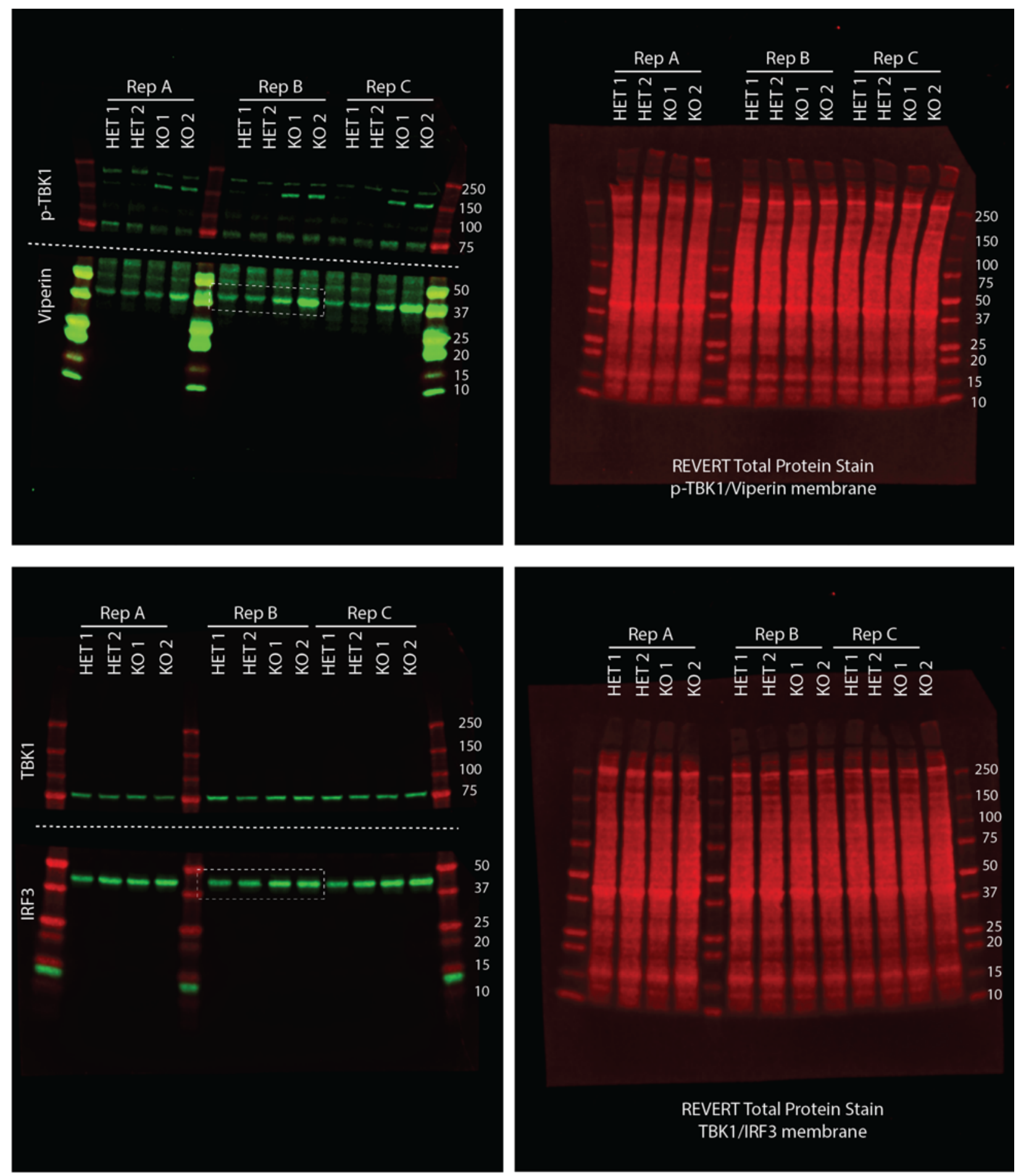



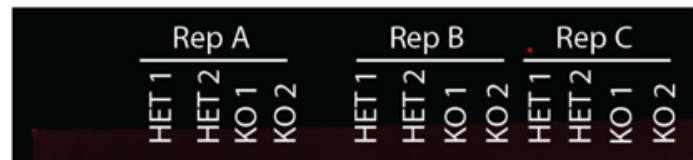

REVERT Total Protein Stain

STAT1/p-IRF3 membrane

Figure S3: Full immunoblots for Figure 3. Three independent experiments were run

on the same gels. Replicate B is shown in figure 3 as indicated by the white boxes. 
REVERT Total Protein Stain was used as a loading control for each membrane. TBK1, phosph-172-TBK1, and STING were also probed.

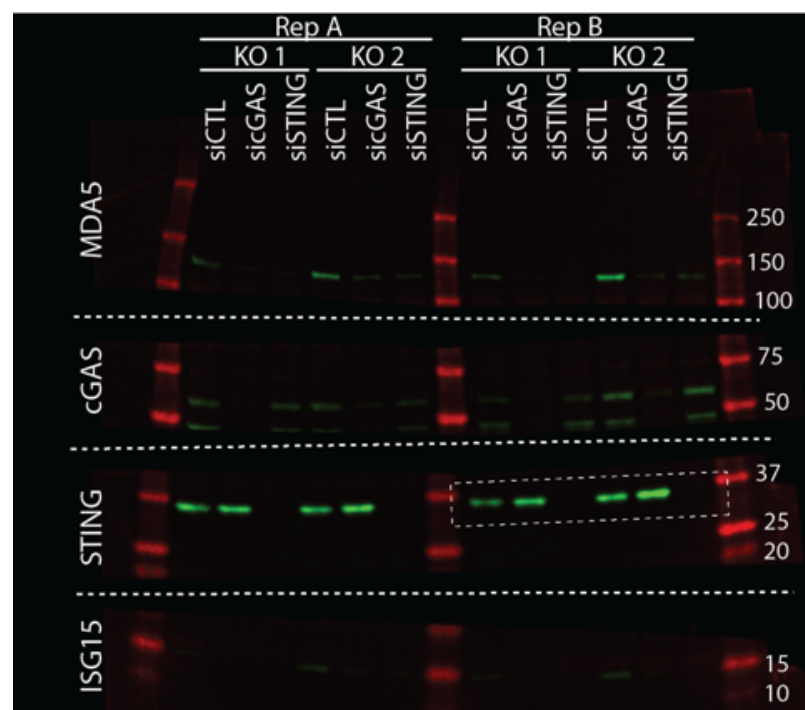

Lower "exposure"

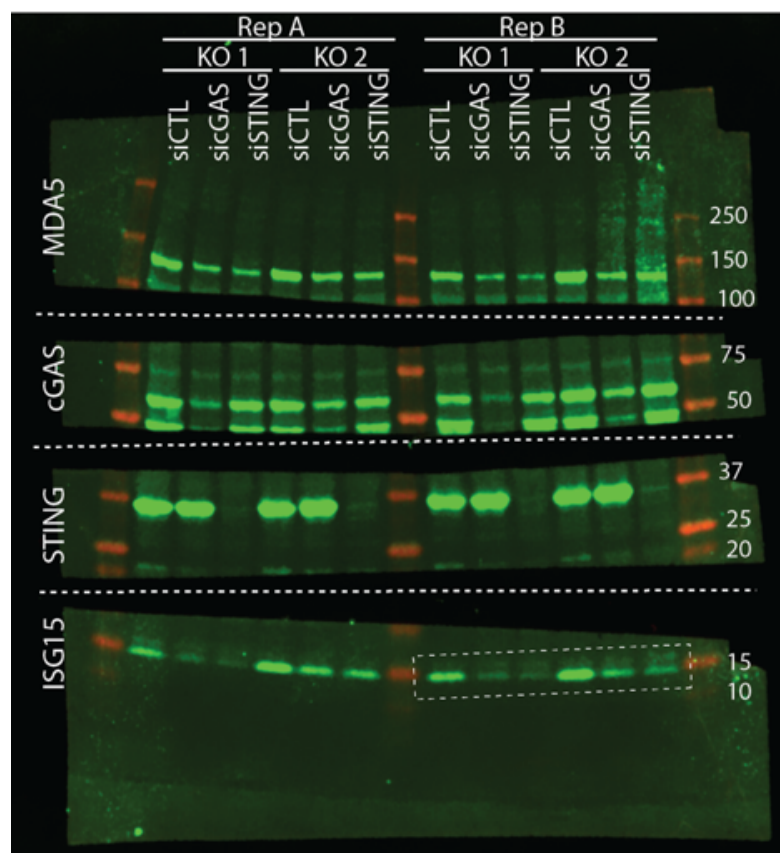

Higher "exposure"

bioRxiv preprint doi: https://doi.org/10.1101/2020.03.02.972513; this version posted March 2, 2020. The copyright holder for this preprint

(which was not certified by peer review) is the author/funder, who has granted bioRxiv a license to display the preprint in perpetuity. It is made available under aCC-BY-NC-ND 4.0 International license.

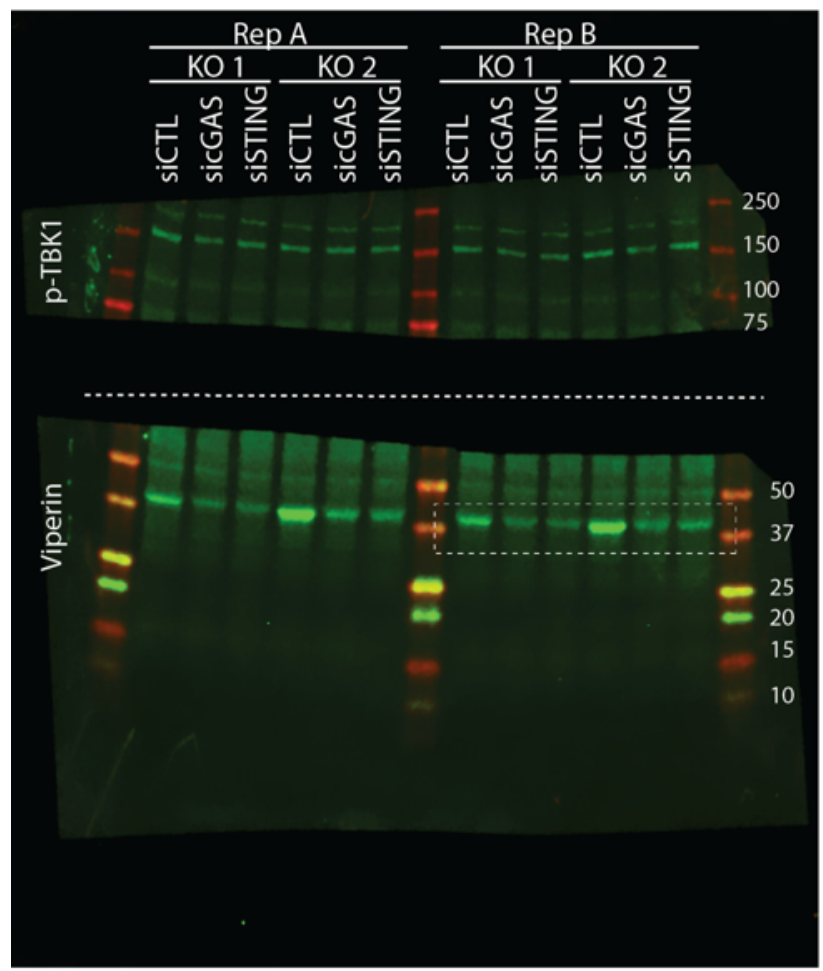

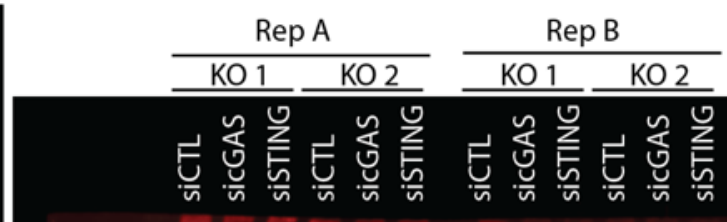

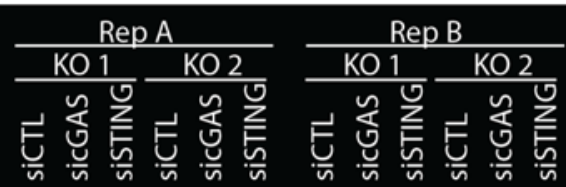

REVERT Total Protein Stain p-TBK1/Viperin Membrane
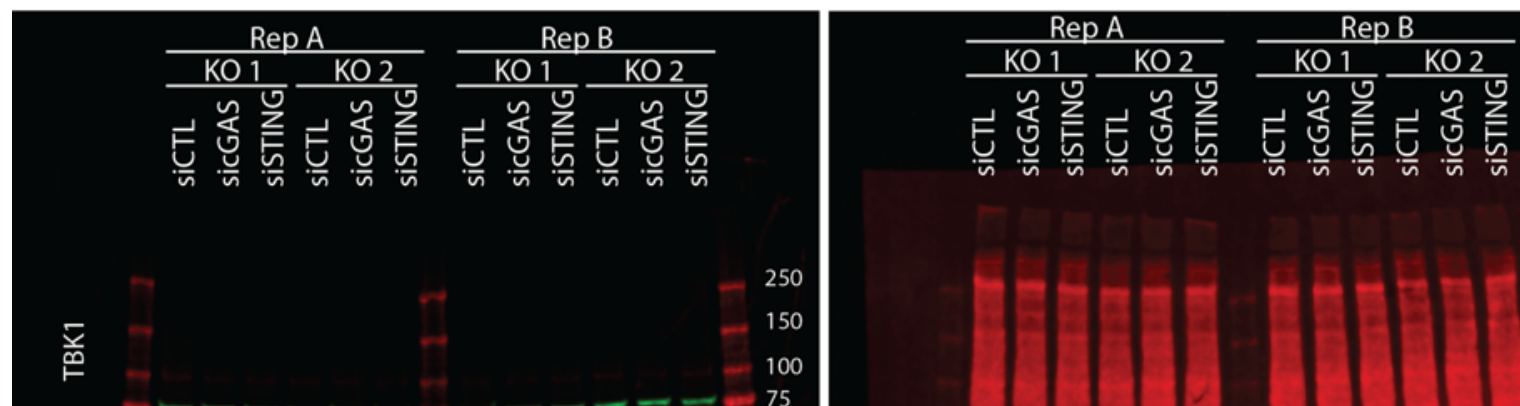
(1) - 75

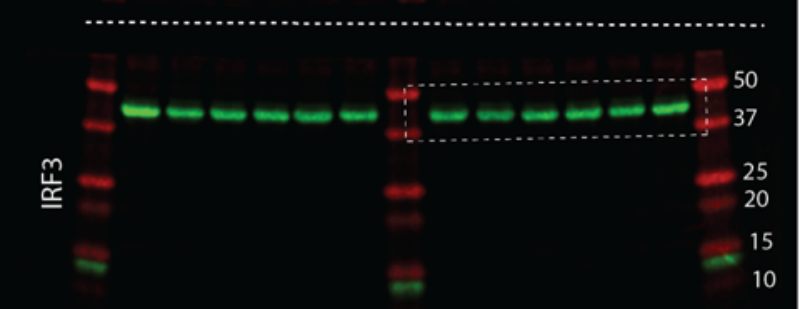



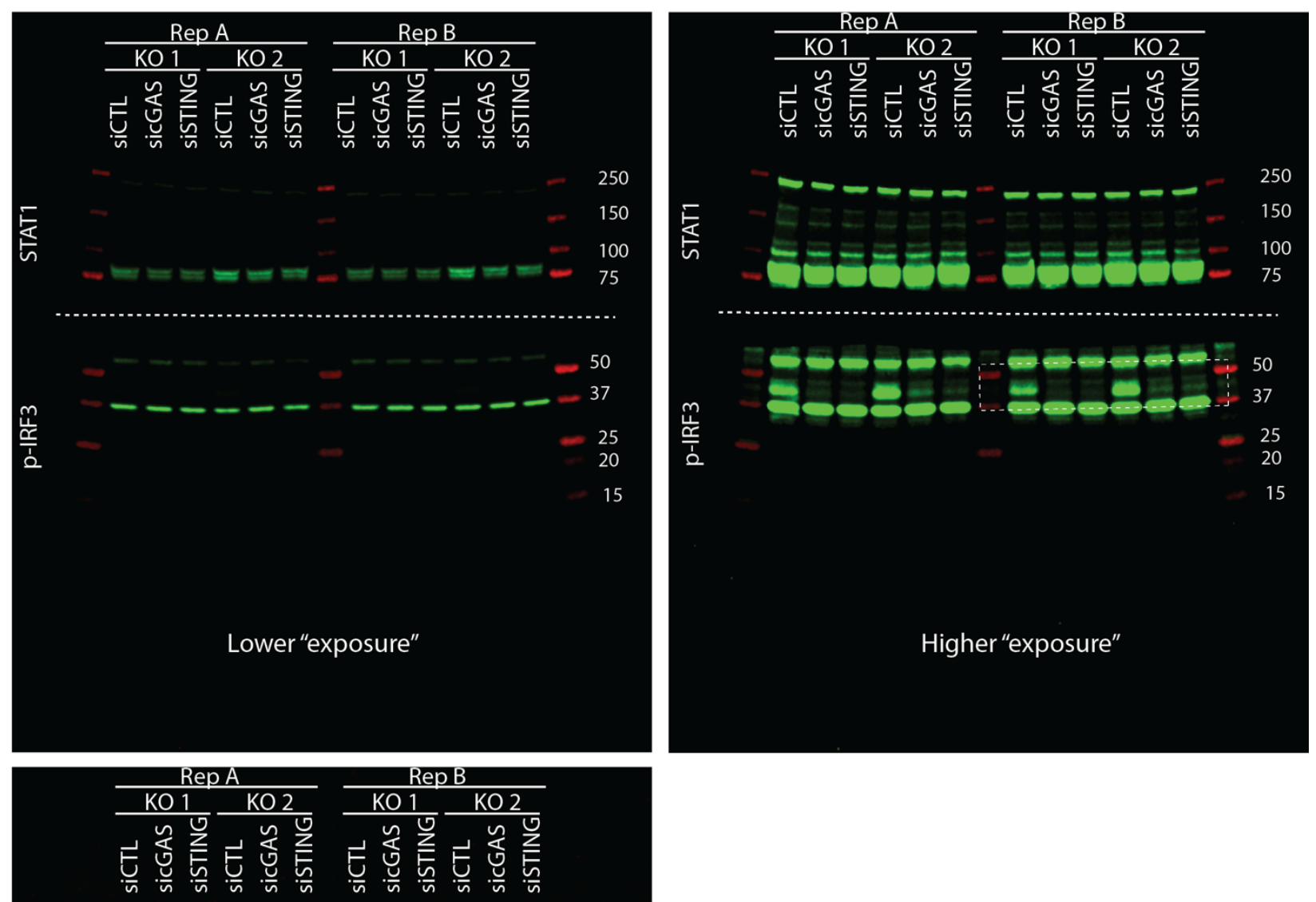

REVERT Total Protein Stain STAT1/p-IRF3 Membrane

Figure S4: Full immunoblots for Figure 4. Two independent experiments were run on the same gels. Replicate B is shown in figure 4 as indicated by the white boxes.

REVERT Total Protein Stain was used as a loading control for each membrane. TBK1, phosph-172-TBK1, and STING were also probed. 


\section{REFERENCES}

1. Lange SS, Takata K, Wood RD (2011) DNA polymerases and cancer. Nature reviews. Cancer 11: 96-110. doi:10.1038/nrc2998

2. Martin SK, Wood RD (2019) DNA polymerase $\zeta$ in DNA replication and repair. Nucleic Acids Res 47: 8348-8361. doi:10.1093/nar/gkz705

3. Bemark M, Khamlichi AA, Davies SL, Neuberger MS (2000) Disruption of mouse polymerase zeta (Rev3) leads to embryonic lethality and impairs blastocyst development in vitro. Current biology : CB 10: 1213-1216.

4. Esposito G, Godindagger I, Klein U, Yaspo ML, Cumano A, Rajewsky K (2000) Disruption of the Rev3l-encoded catalytic subunit of polymerase zeta in mice results in early embryonic lethality. Current biology : $C B$ 10: 1221-1224.

5. Wittschieben J, Shivji MK, Lalani E, Jacobs MA, Marini F, Gearhart PJ, Rosewell I, Stamp G, Wood RD (2000) Disruption of the developmentally regulated Rev3/ gene causes embryonic lethality. Current biology : CB 10: 1217-1220.

6. Wittschieben JP, Patil V, Glushets V, Robinson LJ, Kusewitt DF, Wood RD (2010) Loss of DNA polymerase zeta enhances spontaneous tumorigenesis. Cancer Res 70: 2770-2778. doi:10.1158/0008-5472.CAN-09-4267

7. Schenten D, Kracker S, Esposito G, Franco S, Klein U, Murphy M, Alt FW, Rajewsky $\mathrm{K}$ (2009) Pol zeta ablation in B cells impairs the germinal center reaction, class switch recombination, DNA break repair, and genome stability. J Exp Med 206: 477-490. doi:10.1084/jem.20080669

8. Daly J, Bebenek K, Watt DL, Richter K, Jiang C, Zhao ML, Ray M, McGregor WG, Kunkel TA, Diaz M (2012) Altered Ig Hypermutation Pattern and Frequency in Complementary Mouse Models of DNA Polymerase $\zeta$ Activity. Journal of immunology 188: 5528-5537. doi:10.4049/jimmunol.1102629

9. Lange SS, Bhetawal S, Reh S, Powell KL, Kusewitt DF, Wood RD (2018) DNA polymerase $\zeta$ deficiency causes impaired wound healing and stress-induced skin pigmentation. Life science alliance doi:10.26508/lsa.201800048

10. Lange SS, Bedford E, Reh S, Wittschieben JP, Carbajal S, Kusewitt DF, DiGiovanni $J$, Wood RD (2013) Dual role for mammalian DNA polymerase $\zeta$ in maintaining genome stability and proliferative responses. Proc Natl Acad Sci U S A 110: E687-696. doi:10.1073/pnas. 1217425110

11. Lange SS, Wittschieben JP, Wood RD (2012) DNA polymerase $\zeta$ is required for proliferation of normal mammalian cells. Nucleic Acids Res 40: 4473-4482. doi:10.1093/nar/gks054 
12. Wittschieben JP, Reshmi SC, Gollin SM, Wood RD (2006) Loss of DNA polymerase $\zeta$ causes chromosomal instability in mammalian cells. Cancer Res 66: 134-142. doi:10.1158/0008-5472.CAN-05-2982

13. O-Wang J, Kajiwara K, Kawamura K, Kimura M, Miyagishima H, Koseki H, Tagawa M (2002) An essential role for REV3 in mammalian cell survival: absence of REV3 induces p53-independent embryonic death. Biochemical and biophysical research communications 293: 1132-1137. doi:10.1016/s0006-291x(02)00341-8

14. Van Sloun PP, Varlet I, Sonneveld E, Boei JJ, Romeijn RJ, Eeken JC, De Wind N (2002) Involvement of mouse Rev3 in tolerance of endogenous and exogenous DNA damage. Mol Cell Biol 22: 2159-2169. doi:10.1128/mcb.22.7.2159-2169.2002

15. Lee YS, Gregory MT, Yang W (2014) Human Pol $\zeta$ purified with accessory subunits is active in translesion DNA synthesis and complements Pol $\eta$ in cisplatin bypass. Proc Natl Acad Sci U S A 111: 2954-2959. doi:10.1073/pnas.1324001111

16. Tisserand J, Khetchoumian K, Thibault C, Dembele D, Chambon P, Losson R (2011) Tripartite motif 24 (Trim24/Tif1alpha) tumor suppressor protein is a novel negative regulator of interferon (IFN)/signal transducers and activators of transcription (STAT) signaling pathway acting through retinoic acid receptor alpha (Raralpha) inhibition. The Journal of biological chemistry 286: 33369-33379.

doi:10.1074/jbc.M111.225680

17. Lange SS, Tomida J, Boulware KS, Bhetawal S, Wood RD (2016) The Polymerase Activity of Mammalian DNA Pol $\zeta$ Is Specifically Required for Cell and Embryonic Viability. PLoS genetics 12: e1005759. doi:10.1371/journal.pgen.1005759

18. Ablasser A, Chen ZJ (2019) cGAS in action: Expanding roles in immunity and inflammation. Science 363: eaat8657. doi:10.1126/science.aat8657

19. Prabakaran T, Bodda C, Krapp C, Zhang BC, Christensen MH, Sun C, Reinert L, Cai Y, Jensen SB, Skouboe MK, et al. (2018) Attenuation of cGAS-STING signaling is mediated by a p62/SQSTM1-dependent autophagy pathway activated by TBK1. Embo $j$ 37: e97858. doi:10.15252/embj.201797858

20. Gonugunta VK, Sakai T, Pokatayev V, Yang K, Wu J, Dobbs N, Yan N (2017) Trafficking-Mediated STING Degradation Requires Sorting to Acidified Endolysosomes and Can Be Targeted to Enhance Anti-tumor Response. Cell Rep 21: 3234-3242. doi:10.1016/j.celrep.2017.11.061

21. Yoneyama M, Suhara W, Fujita T (2002) Control of IRF-3 activation by phosphorylation. J Interferon Cytokine Res 22: 73-76.

doi:10.1089/107999002753452674

22. Panne D, McWhirter SM, Maniatis T, Harrison SC (2007) Interferon regulatory factor 3 is regulated by a dual phosphorylation-dependent switch. The Journal of biological chemistry 282: 22816-22822. doi:10.1074/jbc.M703019200 
23. Mackenzie KJ, Carroll P, Lettice L, Tarnauskaite Z, Reddy K, Dix F, Revuelta A, Abbondati E, Rigby RE, Rabe B, et al. (2016) Ribonuclease H2 mutations induce a cGAS/STING-dependent innate immune response. EMBO J 35: 831-844.

doi:10.15252/embj.201593339

24. Mackenzie KJ, Carroll P, Martin CA, Murina O, Fluteau A, Simpson DJ, Olova N, Sutcliffe H, Rainger JK, Leitch A, et al. (2017) cGAS surveillance of micronuclei links genome instability to innate immunity. Nature 548: 461-465. doi:10.1038/nature23449

25. Reislander T, Lombardi EP, Groelly FJ, Miar A, Porru M, Di Vito S, Wright B, Lockstone H, Biroccio A, Harris A, et al. (2019) BRCA2 abrogation triggers innate immune responses potentiated by treatment with PARP inhibitors. Nature communications 10: 3143. doi:10.1038/s41467-019-11048-5

26. Gratia M, Rodero MP, Conrad C, Bou Samra E, Maurin M, Rice GI, Duffy D, Revy $\mathrm{P}$, Petit F, Dale RC, et al. (2019) Bloom syndrome protein restrains innate immune sensing of micronuclei by cGAS. J Exp Med 216: 1199-1213.

doi:10.1084/jem.20181329

27. West AP, Khoury-Hanold W, Staron M, Tal MC, Pineda CM, Lang SM, Bestwick M, Duguay BA, Raimundo N, MacDuff DA, et al. (2015) Mitochondrial DNA stress primes the antiviral innate immune response. Nature 520: 553-557. doi:10.1038/nature14156

28. Coquel F, Silva MJ, Techer H, Zadorozhny K, Sharma S, Nieminuszczy J, Mettling C, Dardillac E, Barthe A, Schmitz AL, et al. (2018) SAMHD1 acts at stalled replication forks to prevent interferon induction. Nature 557: 57-61. doi:10.1038/s41586-018-00501

29. Singh B, Li X, Owens KM, Vanniarajan A, Liang P, Singh KK (2015) Human REV3 DNA Polymerase $\zeta$ Localizes to Mitochondria and Protects the Mitochondrial Genome. PLoS One 10: e0140409. doi:10.1371/journal.pone.0140409

30. Glück S, Guey B, Gulen MF, Wolter K, Kang T-W, Bridgeman A, Rehwinkel J, Zender L, Ablasser A (2017) Innate immune sensing of cytosolic chromatin fragments through cGAS promotes senescence. Nature cell biology 19: 1061.

doi:doi:10.1038/ncb3586

31. Yang H, Wang H, Ren J, Chen Q, Chen ZJ (2017) cGAS is essential for cellular senescence. Proc Natl Acad Sci U S A 114: E4612-e4620.

doi:10.1073/pnas.1705499114

32. Lau L, Gray EE, Brunette RL, Stetson DB (2015) DNA tumor virus oncogenes antagonize the cGAS-STING DNA-sensing pathway. Science 350: 568-571. doi:10.1126/science.aab3291

33. Sail V, Rizzo AA, Chatterjee N, Dash RC, Ozen Z, Walker GC, Korzhnev DM, Hadden MK (2017) Identification of Small Molecule Translesion Synthesis Inhibitors 
That Target the Rev1-CT/RIR Protein-Protein Interaction. ACS Chem Biol 12: 19031912. doi:10.1021/acschembio.6b01144

34. Xu X, Xie K, Zhang XQ, Pridgen EM, Park GY, Cui DS, Shi J, Wu J, Kantoff PW, Lippard SJ, et al. (2013) Enhancing tumor cell response to chemotherapy through nanoparticle-mediated codelivery of siRNA and cisplatin prodrug. Proc Natl Acad Sci U S A 110: 18638-18643. doi:10.1073/pnas. 1303958110

35. Berdis AJ (2008) DNA polymerases as therapeutic targets. Biochemistry 47: 82538260. doi:10.1021/bi801179f

36. Wojtaszek JL, Chatterjee N, Najeeb J, Ramos A, Lee M, Bian K, Xue JY, Fenton BA, Park H, Li D, et al. (2019) A Small Molecule Targeting Mutagenic Translesion Synthesis Improves Chemotherapy. Cell 178: 152-159 e111. doi:10.1016/j.cell.2019.05.028

37. Tomida J, Takata K, Lange SS, Schibler AC, Yousefzadeh MJ, Bhetawal S, Dent SY, Wood RD (2015) REV7 is essential for DNA damage tolerance via two REV3L binding sites in mammalian DNA polymerase $\zeta$. Nucleic Acids Res 43: 1000-1011. doi:10.1093/nar/gku1385

38. Huang da W, Sherman BT, Lempicki RA (2009) Bioinformatics enrichment tools: paths toward the comprehensive functional analysis of large gene lists. Nucleic Acids Res 37: 1-13. doi:10.1093/nar/gkn923

39. Huang da W, Sherman BT, Lempicki RA (2009) Systematic and integrative analysis of large gene lists using DAVID bioinformatics resources. Nat Protoc 4: 44-57. doi:10.1038/nprot.2008.211 